\title{
2. ANALOGÍA Y TEOLOGÍA EN EL MAESTRO ECKHART
}

\section{INTRODUCCIÓN}

Aunque pertenecía más a la escuela de san Alberto Magno, el Maestro Juan Eckhart sigue con mucho respeto a santo Tomás de Aquino, y podemos verlo en el aprecio por la doctrina de la analogía para hacer teología. Ciertamente, tiene una manera muy personal de usar la analogía, pero está en plena concordancia con la del Aquinate, a quien se puede decir que continúa.

Y es que algo muy típico de la Edad Media fueron sus místicos, no solo en el cristianismo, sino en otras religiones; pero aquí abordaremos un ejemplo que marcó las épocas posteriores: Eckhart. Es uno de los grandes inspiradores y teóricos de varias corrientes, desde los místicos del Rin hasta santa Teresa y san Juan de la Cruz en España.

Eckhart encarna la tradición de la llamada escuela albertina o de san Alberto Magno, de Colonia, en tierras alemanas (Moliner, 1974, pp. 229-237). Sobre todo, es sabido que Eckhart influye en los místicos del Rin, y se ha dicho que, a través de ellos, influye en la llamada teología Dutch, o "moderna” (que llega a Lutero), y con esa teología germano-flamenca se asocia a Kempis. 


\section{VIDA Y OBRA DEL MAESTRO ECKHART}

Juan Eckhart es uno de los principales escritores místicos de la Edad Media. Lo dice ya el apelativo de "el Maestro", que se le daba desde entonces (Beuchot, 1982, pp. 1-30). Nació en Hochheim (Turingia, Alemania) alrededor de 1260. Como la mayoría de sus datos cronológicos, la fecha de su ingreso en la Orden de Predicadores, o de los Dominicos, es imprecisa, pudiendo situarse en 1276. Toma el hábito en el célebre convento de Erfurt. Realiza en Estrasburgo lo principal de su formación, y se ordena en 1285. Pasa a perfeccionar sus estudios de teología a Colonia, de 1286 a 1288, fecha en que se pierde su rastro, hasta que aparece en 1298 como prior de Erfurt y vicario general de Turingia.

En 1299 o 1300 es enviado a París, donde explica el libro de texto de teología, a saber, las Sentencias de Pedro Lombardo, y en 1302 recibe el grado de Maestro, título con el cual es tradicionalmente conocido. Cuando en 1303 se divide la provincia de Alemania, demasiado extensa, en dos provincias - la de Sajonia y la de Teutonia-, Eckhart es elegido provincial de la primera. Es reelegido en este cargo en 1307, y, además, se le añade el de vicario de Bohemia. En 1311 vuelve a enseñar en París. De ahí pasa a Estrasburgo en 1314, donde comienza su fama de predicador. Luego, en 1320 va a Colonia para enseñar, y es donde tiene como discípulo a otro gran místico, el beato Enrique Susón.

Su prestigio de gran predicador crece, pero, en 1326, es llamado a proceso, bajo la sospecha de herejía, por el arzobispo de Colonia, Enrique de Virneburgo. Eckhart, consciente de que por ser religioso está exento del tribunal episcopal, apela a la curia pontificia, entonces en Aviñón. Al ser denegada su petición, Eckhart se somete al tribunal de Colonia, y el 13 de febrero de ese año lee públicamente 
su retractación de las proposiciones condenadas, en la iglesia de los dominicos de dicha ciudad (Saranyana, 1989, vol. XXI, fasc. 3, pp. 887 y ss.).

Después, marcha él mismo a Aviñón, para que una comisión papal examine sus obras. No pudo ver el final del proceso, ya que murió antes del fallo final. Su muerte se coloca, con imprecisión, entre 1327 y 1328. Y, de acuerdo al dictamen de la comisión examinadora, Juan XXII, en su bula In agro dominico, del 27 de marzo de 1329 , condena 28 proposiciones tomadas de sus obras, aclarando que las condena "tal como suenan", y que Eckhart se sometió siempre al dictamen de la Iglesia. Los investigadores actuales han demostrado que la mayoría de tales proposiciones no son en realidad heréticas, sino más bien ambiguas y extrañas por la forma en que estaban expresadas.

Su obra es extensa. Además de comentarios al Padrenuestro, a las Sentencias, de Pedro Lombardo, y de algunas Cuestiones disputadas, redactó un gran escrito en latín, la Obra tripartita, consistente en interpretaciones de la Biblia y altas elucubraciones teológicas. Pero su doctrina mística se recoge, sobre todo, en sus obras alemanas, como los Discursos de la distinción, El libro del consuelo divino y los Sermones alemanes (también se le adjudica una Defensa de sus escritos). En cuanto a los sermones, que tantas sospechas le atrajeron, conviene decir que no todo en ellos es de Eckhart, y que hay muchos problemas sobre la autenticidad de los contenidos. Esto se debe a que no los escribió el propio Eckhart, sino algunos de los oyentes. Podemos pensar, por ejemplo, en que alguien, al estar escuchando el sermón, lo reprodujo de manera taquigráfica, con el peligro consiguiente de grandes lagunas y tergiversaciones. 


\section{SU DOCTRINA TEOLÓGICA Y MÍSTICA}

Los textos de sus tratados y sermones responden a los rasgos capitales de su doctrina mística, que pueden esquematizarse en tres apartados: 1) la procedencia de las creaturas de Dios, o la creación; 2) el retorno de las creaturas a Dios, en especial la creatura humana, es decir, la justificación, y 3) la unión del alma con Dios, o la glorificación divinizante del alma por parte de Dios. Este último apartado es, por supuesto, el más importante ${ }^{1}$.

Eckhart toma muy en cuenta a santo Tomás, pero lleva algunas de sus tesis a una gran radicalidad. Además, recoge muchas cosas del neoplatonismo, que ya venían en la escuela albertina o de san Alberto Magno, a través del Pseudo-Dionisio. También retoma de Alberto y Tomás la doctrina de la analogía, que aplica de manera muy personal, usando la analogía de proporcionalidad, pero más la de atribución, para marcar de manera más fuerte la diferencia entre Dios y las creaturas, es decir, la trascendencia absoluta de Dios y su infinita superioridad en relación con lo creado.

En Dios, Eckhart considera como lo más elevado la unidad y la inteligencia, y coloca a esta última incluso con más rango que el ser, a diferencia de lo que hacía el Aquinate. Dios es porque conoce, dice con sabor a Berkeley. A través del Liber de causis, conoce la tesis neoplatónica de que la primera creatura es el ser; por ello, el ser no puede ser lo primero, requiere algo anterior, que es el entendimiento divino, este crea el ser, el cual causa todas las demás creaturas y, entre ellas, al hombre. Dios es perfecta Unidad e Inteligencia, ambas hipostasiadas (Eckhart, 1998, pp. 102-103). Eckhart contrapone el ser no a la esencia, como Tomás, sino al ente; es una relación del ser

Una buena exposición de la doctrina eckhartiana, en Klein (1978) y Haas (2002). Los sigo en varios puntos. 
y el ente, que suena a Heidegger ${ }^{2}$. Esa relación entre el ser y el ente se da según la analogía, con el ser proporcionado a cada ente, con lo cual evita el monismo (que vendría si la relación fuera unívoca). $\mathrm{Y}$, al decir que Dios es el mismo entender, escapa del panteísmo. En Dios no hay ente ni ser, está más allá de ellos, con lo cual evita la acusación heideggeriana de incurrir en ontoteología. En efecto, Dios crea el ser (la primera de las creaturas en el neoplatonismo, por ejemplo el del Pseudo-Dionisio), y, en ese momento, crea las demás cosas.

En Dios Trino, esto es, en Dios como Trinidad (Padre, Hijo y Espíritu Santo), Eckhart encuentra que esta está muy vinculada a la doctrina de la gracia (Eckhart, 1998, pp. 96-98). En efecto, la gracia es la presencia de la Trinidad en el hombre. Eckhart acepta que Dios es uno en esencia y trino en personas; pero recalcó tanto la unidad de Dios que a sus jueces les pareció que ponía en peligro la Trinidad de personas. A veces, es tan neoplatónico que habla de la procesión del Hijo a partir de Dios y de la del Espíritu a partir de ambos casi como una emanación, por lo que volvía a vérselo como panteísta. El Padre es principio o entendimiento, el Hijo es vida o verdad y el Espíritu Santo es el ser en plenitud de la divinidad. Hay incluso un como núcleo de la divinidad o de la Trinidad, común a todas las tres personas.

En cuanto a la creación, Eckhart nos dice que está presidida por el amor, según el cual Dios crea todas las cosas y estas tienden a Él. A pesar de algunas fórmulas con cierto sabor a emanatismo y, en el fondo, a panteísmo, Eckhart solo quiere resaltar la dependencia que todo guarda con respecto a Dios, pues, también insiste siempre en que hay una distinción infinita entre Dios y las creaturas. Dios, comparado con las creaturas, es todo, y ellas son como nada.

2 De hecho, el gran filósofo alemán puso su atención en Eckhart, véase Heidegger (1997, pp. 170-173). 
Yendo más allá que san Agustín, dice que, en el hombre, también el intelecto es lo más elevado, por lo que el conocimiento humano es como algo que Dios hace en él. Dios hace ser al alma humana al hacerla entender. Esta iluminación divina es la causa de la existencia humana, al mismo tiempo que de su conocimiento (Beuchot, 1996, pp. 258 y ss.).

Conforme con el amor que Dios les profesa y les da, todas las creaturas tienden hacia Él, y, en especial, el hombre. Para reunirse con Dios, el hombre debe encontrarlo en la parte más íntima del alma, y para eso tiene que despojarse del apego a lo que no es Dios, tiene que vaciarse de todas las cosas, incluso de sí mismo. Solo así tendrá pobreza de espíritu y pureza de corazón, y se encontrará lleno de Dios. A las autoridades eclesiásticas les pareció que estaba afirmando la transformación del hombre en Dios, pero es solo por participación, a través de esa iluminación con la que las hace ser y conocer. Y, sobre todo, como Dios no es ente ni ser, y las almas tienen ente y ser, Él no puede darles su ser, puesto que pertenece a un orden distinto del ser y más elevado. Al unir el alma a sí, Dios no deja de ser Uno ni de ser Inteligencia.

Precisamente, aquí pone Eckhart las funciones de las tres personas divinas de la Santísima Trinidad. El Padre engendra al Hijo en el hondón del alma humana, y todos vienen por él a hacer su morada en el hombre. Necesariamente, ese aspecto común y como nuclear de la Trinidad es con la que se conecta el hombre espiritual. Esta inhabitación de la Trinidad en el hombre lo hace recuperar la imagen de Dios, perdida por el pecado. La unión con Dios Trino es contemplativa y activa, cognoscitiva y amorosa, en ella el hombre "noble" o justo se une a cada una de las tres personas y con todas ellas al unísono. Allí el hombre escucha el nombre desconocido de Dios, que es el que resalta la Unidad de la Trinidad. Y es una unión 
no solo contemplativa, sino activa, porque el hombre, gracias a ella, se entrega a los demás hombres, sus prójimos. Es el desasimiento de lo terreno y el servicio a los otros seres humanos (Eckhart, 1998, pp. 34-38 y 77-89). Tiene que haber obras de amor, de caridad, por las cuales se manifiesta que hay amor a Dios. Pero esas obras exteriores están fundamentadas en la obra interior, y provienen de ella como de una fuente.

Además del desasimiento, Eckhart pone como condición de la unión la pureza del corazón. Es decir, radica todo en el interior del hombre. Las obras exteriores, de penitencia y mortificación, son solo una ayuda para lograr la obra interior, que es la que cuenta (1998, pp. 68-74). Por eso, en esa doctrina eckhartiana de la gracia van unidas la justificación y la glorificación, vienen a ser lo mismo, o la segunda es continuación de la primera. La obra interior del hombre consiste en que Dios produzca en él su imagen y semejanza, esto es, el análogon, que es lo mismo que el proceso por el que engendra en el hombre a su Hijo divino. Solo Dios tiene propiamente la justicia, pero por analogía de atribución el hombre participa de ella, y es hecho justo, es justificado. Ya por un análogon suyo, Dios está presente en todas las creaturas. Pero de manera especial está en el hombre. Está en el hondón del alma, en el fondo de ella. Ese estar de Dios en el hombre es una liberación del egoísmo, lo libera de las creaturas y de sí mismo, es una libertad con respecto a todas las creaturas, sobre todo, con respecto a sí mismo, para solo centrarse en Dios, aspirar a Él y tenerlo.

Y, cuando el hombre tiene a Dios, Él se unirá tan íntimamente a su alma que la dejará participar de su gloria; el alma rebosa de beatitud con esa presencia íntima de Dios que, según la fórmula de Eckhart, llega en cierta manera a divinizarse (1998, pp. 116-117). No se trata, empero, de panteísmo, ni siquiera de panenteísmo; Dios está en el 
hombre por participación, no por esencia. No hay una identificación, sino una participación. Porque, entonces, el hombre está justificado; pero no por una justificación suya, sino por una ajena: la de Dios, que le es dada por participación y por analogía, tanto de atribución como de proporcionalidad. El conocimiento y, sobre todo, el amor, unen el alma a Dios con una felicidad que preludia el cielo. Su contemplación y su acción serán siempre según Dios, y en esto se vive ya desde ahora el Reino de los Cielos. Tal es la doctrina de Eckhart, recogida en los diversos textos de sus tratados y sermones.

\section{CARÁCTER ANALÓGICO DE LA TEOLOGÍA ECKHARTIANA}

Por todo lo anterior, captamos el carácter analógico de la teología de Eckhart. Aunque, según la escuela de san Alberto, está más en la línea neoplatónica que en la aristotélica, sigue a santo Tomás, en ese aprecio por la analogicidad del lenguaje sobre Dios.

Es el que también usa para expresar su experiencia mística. No olvidemos que santo Tomás era igualmente místico, pero sin dejar de ser consumado teólogo. En Eckhart resplandece más el místico sobre el teólogo, pero también se detecta su carácter eminentemente analógico.

Hay toda una hermenéutica analógica en Eckhart, por la que hacía una teología analógica también, en la línea neoplatónica del Pseudo-Dionisio Areopagita, pero también en la línea aristotélica de santo Tomás. El propio Aquinate admitió, igualmente, elementos platónicos en su sistema. La analogía misma lo ayudaba a darles el adecuado equilibrio. Es lo que asimismo se refleja en el Maestro Eckhart: su maestría, su magisterio, reside en construir un sistema o, 
si se prefiere, una síntesis bien lograda entre la mística y la teología. Y ello gracias a la virtud poderosa que tiene la analogía para dar a la teología la capacidad de ser sintética después de haber sido analítica.

La fuerte presencia de lo místico en Eckhart hace que su teología sea muy significativa. Tiene una sobrecarga de sentido, que es propia del símbolo. Es una teología simbólica, que requiere de una hermenéutica analógica para ser descifrada correctamente, en toda su riqueza, porque así, con esa analogicidad, fue escrita. Los sermones de nuestro místico dominico revelan un uso excelente de la metáfora y la parábola, ingredientes analógicos que dan una gran vitalidad a la construcción teológica, de modo que no sea fría y seca, sino cálida y estimulante, es decir, cargando la fe de amor o caridad y de esperanza.

Esa hermenéutica analógica de Eckhart se ve, sobre todo, en la exégesis bíblica que hace. La necesita para su predicación, para sus sermones, lo mismo que para sus tratados. En unos y en otros se ve la riqueza de su pensamiento, pues, un sermón suyo, por pequeño que sea, está cargado de enseñanzas, al igual que los tratados, a veces extensos, que dejó para instrucción de los frailes, y que hacen buena corte a los sermones, que eran más bien para la gente sencilla a la que predicaba, y que, sin embargo, están llenos de doctrina, por lo mismo que están llenos de experiencia espiritual profunda y plena.

La hermenéutica analógica ayuda a Eckhart a equilibrar el sentido literal y el sentido alegórico, al igual que lo había hecho con santo Tomás. El teólogo alemán tiene la capacidad literal de hacer una teología muy seria, pero también la capacidad alegórica o alegorizante para introducir la metáfora, la parábola y otros recursos analógicos para expresar su vivencia mística. De esta manera, lee las Sagradas Escrituras modulando el sentido alegórico o simbólico, que le hace entresacar la riqueza simbológica que hay en ellas, 
pero también el sentido literal que despliega en sus tratados, más de índole escolástico. Al igual que Tomás, entrecruza y conjunta la exégesis de los monjes, que era más mística y, por lo mismo, alegórica, con la de los escolásticos, más filosófica y, por ende, tendiente a la literalidad. Es, a semejanza del Aquinate, un teólogo muy completo, por amalgamar la racionalidad escolástica con la mística monástica.

\section{CONCLUSIÓN}

Eckhart fue marcador del espíritu en su época, y lo es hasta la actualidad. Perteneció a la escuela de san Alberto Magno. Lo importante es que ha sido paradigma inmortal de la mística cristiana, no solo medieval. Es un buen botón de muestra de esta espiritualidad cristiana, y de los más influyentes. Eckhart fue más teórico que práctico, pero sumamente experimental, pues, de la experiencia se nutre la teología espiritual, y toda teología. Fue maestro insigne del pensamiento en su modalidad teológica.

Y puede decirse que tuvo una hermenéutica propiamente analógica, ya que supo equilibrar el sentido alegórico de la Escritura con el sentido literal, al menos teniendo a este como referente ideal, como ideal regulativo, que lo hizo mantener siempre la ortodoxia, a pesar de que muchas de sus expresiones sonaron a heterodoxia o rayaron en la herejía. Su iluminación dura hasta la actualidad, y la teología de nuestra época se vería altamente beneficiada si atendiera a la hermenéutica analógica que estructuró Eckhart en seguimiento de Tomás. Ambos fueron paradigmas analogistas. 